\title{
Knowledge Regarding Secondary Prevention Lifestyle Practices Among Patients with Ischaemic Heart Disease in Oman \\ Pilot study
}

Tamim R. Al-Tamimi, Hafidh A. Ba-Omar, "Sunil Nadar

$$
\begin{gathered}
\text { المعرفة بأنماط الحياة للوقاية الثانوية لدى المصابين بمرض الشريان } \\
\text { التاجي في عمانة استطاعية } \\
\text { الماندان }
\end{gathered}
$$

$$
\text { تميم راشد التميمي، حفيظ الهادي باعمر، سونيل نادر }
$$

ABSTRACT: Objectives: Secondary prevention of ischaemic heart disease (IHD) is very important. This study aimed to assess knowledge of necessary lifestyle changes among Omani patients diagnosed with IHD. Methods: This cross-sectional pilot study took place between October 2015 and February 2016 at the Sultan Qaboos University Hospital (SQUH), Muscat, Oman. A total of 30 random patients with IHD from the Cardiology Outpatient Clinic of SQUH were included. A 30-item survey was used to determine patients' knowledge of necessary lifestyle practices following their IHD diagnosis, with scores of $<70 \%$ indicating poor knowledge. Results: Overall, 21 patients $(70.0 \%)$ had low knowledge levels. Scores ranged from 38.9-94.4\% (mean: 60.7\% $\pm 14.1 \%$ ). No demographic factors were found to predict low scores, although there were some differences in individual questions. Conclusion: Low knowledge levels regarding lifestyle changes were observed among IHD patients in Oman. More efforts should be made to educate these patients for the secondary prevention of IHD.

Keywords: Secondary Prevention; Ischemic Heart Disease; Myocardial Infarction; Healthy Lifestyle; Oman.

$$
\begin{aligned}
& \text { الملخص: الهذف: هناك أهمية شديدة للوقاية الثانوية من مرض الثريان الثرئ التاجي. هدفت هذه الدراسة إلى تقييم معرفة وممارسات }
\end{aligned}
$$

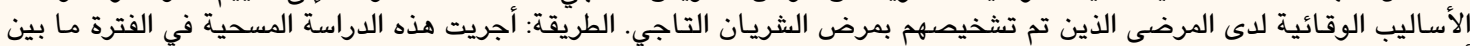

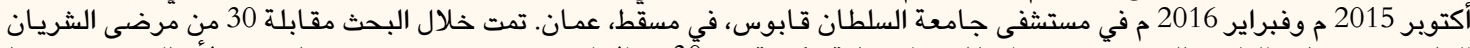

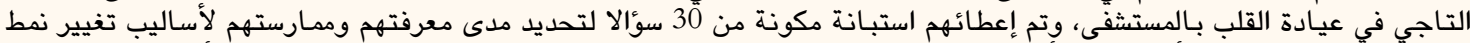

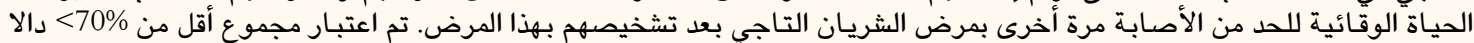

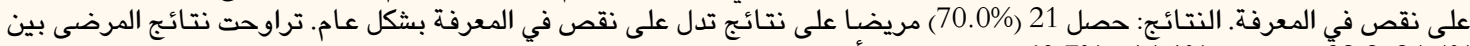

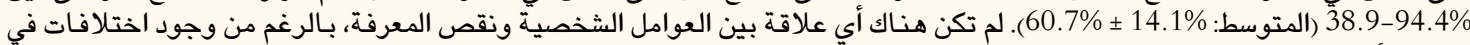

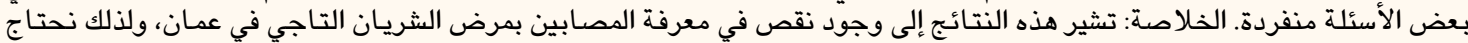

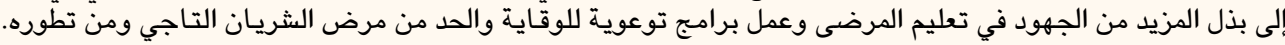

$$
\begin{aligned}
& \text { الكلمات المفتاحية: الوقاية الثانوية؛ مرض الثريان التاجي؛ احتشاء عضلة القلب؛ النمط الحياتي الصحي؛ عمان. }
\end{aligned}
$$

I SCHAEMIC HEART DISEASE (IHD) IS ONE OF THE leading causes of mortality and morbidity worldwide; in 2012, IHD resulted in approximately 7.4 million deaths, accounting for $13 \%$ of all deaths worldwide. ${ }^{1,2}$ In the Middle East, the prevalence of IHD appears to be increasing, while that of other cardiovascular conditions such as rheumatic heart disease appears to be decreasing. ${ }^{3}$ The risk factors involved in the pathogenesis of IHD are classified as either modifiable (e.g. diabetes, hypertension or obesity) or not modifiable (e.g. age, gender or genetic factors). From a public health perspective, modifiable risk factors are very important since changes or alterations to reduce these risk factors can benefit IHD patients. ${ }^{4}$ Certain lifestyle changes-such as the adoption of a Mediterranean-type diet, regular exercise, cessation of smoking and decreased consumption of alcohol-are beneficial in the prevention of IHD. ${ }^{5}$ However, knowledge and motivation on the part of the patient are key to successfully implementing and maintaining necessary lifestyle modifications. ${ }^{6}$

In Oman, previous research has focused on lifestyle changes, knowledge and attitudes regarding primary IHD prevention and has indicated that overall knowledge about disease risk factors is low, particularly among elderly IHD patients. ${ }^{7}$ It is therefore 
unclear whether patients in Oman adopt healthier lifestyles after being diagnosed with a myocardial infarction (MI) or IHD. Moreover, few studies have examined IHD patients' knowledge of lifestyle changes with regards to secondary IHD (i.e. disease recurrence after a previous MI or IHD diagnosis) prevention. This study therefore aimed to investigate knowledge regarding necessary lifestyle modifications linked to IHD risk reduction among Omani patients with a previous diagnosis of MI or IHD. In addition, the study sought to identify factors affecting levels of knowledge of these lifestyle practices. The findings of this study may help in formulating future secondary prevention strategies for IHD in Oman.

\section{Methods}

This cross-sectional pilot study was conducted at the Cardiology Outpatient Clinic of the Sultan Qaboos University Hospital, Muscat, Oman, from October 2015 to February 2016. A randomly chosen sample of 30 patients with IHD seen at the clinic during the study period was included. The inclusion criteria were $>18$-year-old patients with stable IHD and a history of either stable angina or a MI occurring more than six months beforehand. Patients were excluded if they had had a MI in the previous six months or if they had unstable symptoms. In addition, those with terminal illnesses or disabling diseases prohibiting normal exercise were excluded.

For the purposes of the study, a 30-item survey was designed which included 10 demographic questions, 10 multiple choice questions regarding dietary habits and 10 multiple choice questions regarding exercise habits. Existing questionnaires on lifestyle factors were not utilised for this study as it was felt that these previously published questionnaires did not align with the customs and practices of the local Omani population. The survey was initially designed in English and then translated into Arabic, as most people in Oman are Arabic-speaking. However, an English version was made available to the patients at their request. The questionnaire was pre-tested for validity and clarity by non-medical volunteers recruited from patients' relatives and staff of the Sultan Qaboos University. According to the feedback obtained, the survey was then modified before being used in the main pilot study. The survey took a maximum of 10 minutes to complete. For patients who were unable to read, the investigators read the questions and potential responses aloud and gave the participants sufficient time to answer without any prompting, either on the part of relatives or
Table 1: Demographic characteristics of patients with ischaemic heart disease at the Sultan Qaboos University Hospital, Muscat, Oman ( $\mathrm{N}=30)$

\begin{tabular}{lc} 
Characteristic & $\mathbf{n}(\%)$ \\
Age in years & $1(3.3)$ \\
$18-30$ & $3(10.0)$ \\
$31-45$ & $12(40.0)$ \\
$46-60$ & $14(46.7)$ \\
$>60$ & \\
Gender & $21(70.0)$ \\
Male & $9(30.0)$ \\
Female & \\
Education level & $11(36.7)$ \\
Illiterate & $4(13.3)$ \\
Reading/writing & $10(33.3)$ \\
High school & $5(16.7)$ \\
Higher education & $17(56.7)$ \\
Employment status & $13(43.3)$ \\
Employed & $7(23.3)$ \\
Unemployed/retired & $23(76.7)$ \\
Presence of diabetes & \\
Yes & \\
No & \\
Presence of hypertension & \\
Yes & \\
No & \\
Presence of hypercholesterolaemia & $(76.7)$ \\
\hline
\end{tabular}

investigators. A score of $\geq 70 \%$ was defined as adequate knowledge of necessary lifestyle changes.

Data were analysed using the Statistical Package for the Social Sciences (SPSS), Version 21 (IBM Corp., Chicago, Illinois, USA). Subsequently, the data were categorised as necessary for calculating associations. A Chi-squared test was used to determine associations between sociodemographic factors and knowledge levels. A $P$ value of $<0.050$ was considered statistically significant.

The Medical Ethics Committee of the College of Medicine \& Health Sciences at the Sultan Qaboos University gave ethical approval for this study (MREC \#1121). All patients gave informed consent before participating in the study. 
Table 2: Prevalence of self-reported secondary prevention lifestyle changes among patients with ischaemic heart disease at the Sultan Qaboos University Hospital, Muscat, Oman $(\mathrm{N}=30)$

$\begin{array}{lc}\text { Questionnaire item } & \mathbf{n}(\%) \\ \text { How many meals a day do you eat? } & \\ 1-2 & 0(0.0) \\ 3-4 & 23(76.7) \\ >5 & 1(3.3) \\ \text { No response } & 6(20.0)\end{array}$

Do you feel your lifestyle has improved since you were diagnosed with IHD?

$$
\begin{array}{ll}
\text { Yes } & 18(60.0) \\
\text { No } & 12(40.0)
\end{array}
$$

How much of your daily diet is composed of carbohydrates?

$<25 \%$

$20(66.7)$

$25-50 \%$

$10(33.3)$

$>50 \%$

How much of your daily diet is composed of fat?

$\begin{array}{lc}<25 \% & 21(70.0) \\ 25-50 \% & 9(30.0) \\ >50 \% & 0(0.0) \\ \text { How much of your daily diet is composed of protein? } \\ <25 \% & 17(56.7) \\ 25-50 \% & 13(43.3) \\ >50 \% & 0(0.0)\end{array}$

How much of your daily diet is composed of fruit/vegetables?

$<25 \%$

$25-50 \%$

$20(66.7)$

$>50 \%$

Do you mostly eat homemade food?

Yes

$26(86.7)$

No

What type of meat do you eat most often?

Fish

Chicken

Goat or beef

All

$15(50.0)$

Do you smoke?

Yes

No

Do you drink alcohol?

Yes

$0(0.0)$

$30(100.0)$

No
If you were offered the following food items, which one would you choose?

Fried chips

An apple

Pizza

Do you feel you take more care with your diet since your IHD diagnosis?

Yes

$21(70.0)$

No

$9(30.0)$

In your opinion, how do you compare to other people of the same age with regards to physical activity?

More active

Less active

As active

How many times per week do you exercise?

$<2$ times

2-3 times

$4-5$ times

$>5$ times

What type of exercise do you do?

Team sports

Running

Walking

$26(86.7)$

Strength training

Cycling

Would you walk or drive for a distance of $500 \mathrm{~m}$ ?

Drive

Walk

Would you use an elevator if it were available?

Yes

No

How much time do you spend walking daily?

$<1$ hour

1-2 hours

$>2$ hours

How many hours do you sleep at night?

$<5$ hours

5-8 hours

$>8$ hours

Have you exercised more since you were diagnosed with IHD? No

$18(60.0)$

Yes

$12(40.0)$

$I H D=$ ischaemic heart disease 


\section{Results}

All 30 patients included in the study were Omani nationals. The majority of the participants were under 60 years old (53.3\%), male (70.0\%), literate (63.3\%) and unemployed/retired (76.7\%). The majority were not diabetic (76.7\%), but did have hypertension and hypercholesterolemia (56.7\% each) [Table 1]. Overall, 21 participants $(70.0 \%)$ scored $<70 \%$, indicating low levels of knowledge of secondary prevention lifestyle changes. The maximum and minimum scores were $94.4 \%$ and $38.9 \%$, respectively. The mean score was $60.7 \% \pm 14.1 \%$.

With regards to their survey responses, the majority of the patients had made changes to their lifestyle following their IHD diagnosis (60.0\%). In addition, the majority of the patients reported adequately controlling the fat content of their daily diets (70.0\%). However, less than half of the participants exercised more following their diagnosis of IHD (40.0\%). A few participants perceived themselves to be more active than other individuals of the same age (20.0\%). Most participants reported exercising four or more times per week (60.0\%). In general, the type of exercise most preferred was walking (86.7\%). While most participants would choose to walk for a distance of $500 \mathrm{~m}$ instead of using a car (63.3\%), less than half would take the stairs rather than an elevator if one were available (43.3\%). Approximately a third of the participants walked for at least one hour daily (33.3\%) and the majority slept for between 5-8 hours per night (83.3\%) [Table 2].

No significant associations were identified between knowledge scores and sociodemographic factors, including education level or employment status. However, there was a significant association between consumption of fish and education level, with participants who had a high school education eating more fish than those with a lower level of education $(P=0.025)$. In addition, unemployed participants appeared to walk significantly more than those who were employed $(P=0.031)$.

\section{Discussion}

This pilot study was conducted to evaluate knowledge of secondary prevention lifestyle factors among patients diagnosed with IHD in Oman. In general, knowledge of healthy lifestyle practices among the participants was low. While the majority of patients said they were more aware of their diet and exercise habits after their IHD diagnosis, this awareness does not appear to have been translated into practice. One of the reasons for this could be due to misconcep- tions about the disease and the benefits of exercise following a MI or IHD diagnosis. Accordingly, after taking the survey, some of the patients explained that they felt that they should not exercise and put more stress on their hearts. Therefore, it is necessary for health professionals in Oman to emphasise the need to undertake controlled exercise to prevent disease recurrence among patients with IHD.

In the current study, no specific demographic factor was found to be associated with poor levels of knowledge regarding lifestyle changes. This may be due in part to the small sample size, in which statistically significant differences could not be determined. While minor differences in responses between specific questions were observed, this could have been related to the activity itself; for example, unemployed/retired patients may have been found to walk significantly more than employed participants because they had more free time to walk rather than because they had greater knowledge of lifestyle changes. Unfortunately, the patients were not asked to explain why they responded as they did to individual questions and thus the reason for these associations could not be clarified.

Secondary prevention and cardiac rehabilitation are an important part of the management of patients with IHD. ${ }^{8}$ However, most patients are only given a limited amount of verbal information on necessary lifestyle modifications upon discharge from hospital following an acute coronary syndrome diagnosis. In busy outpatient clinics, there is often insufficient time to provide patients with necessary information regarding the disease and the lifestyle changes required to prevent recurrence. In addition, most public health campaigns target the primary prevention of IHD, but often tend to ignore secondary prevention, which is equally important. ${ }^{8}$ Therefore, more emphasis should be placed on the secondary prevention of IHD in Oman, with more health education to be given to IHD patients and the development and implementation of national cardiac rehabilitation facilities.

The current study was subject to some limitations, including the small sample size and the high male-tofemale ratio. In addition, as a cross-sectional study, the findings may not be reliable. The qualitative and self-reported nature of the majority of the questions in the newly created survey tool may also have led to inaccuracies. In general, questionnaire-based studies are subject to response bias, with respondents potentially modifying their responses by overreporting positive behaviours and under-reporting negative behaviours based on what they think is the correct answer, rather than reporting behaviours accurately. ${ }^{9}$ Despite these limitations, the findings of this pilot study are important as they highlight a lack 
of knowledge with regards to lifestyle modifications in a high-risk patient group in Oman. Further studies are recommended with a larger sample size and perhaps based within the general community rather than a busy outpatient clinic in order to better identify patients who would benefit from more intensive health education regarding necessary lifestyle changes.

\section{Conclusion}

According to the results of this pilot study, patients with IHD in Oman have inadequate knowledge of the necessary lifestyle changes required for secondary prevention. As a result, cardiac rehabilitation facilities should be made available to patients with IHD and health professionals should highlight the need for lifestyle modifications to prevent disease recurrence. However, further research on this topic is recommended.

\section{CONFLICT OF INTEREST}

The authors declare no conflicts of interest.

\section{FUNDING}

No funding was received for this pilot study.

\section{References}

1. Writing Group Members, Mozaffarian D, Benjamin EJ, Go AS, Arnett DK, Blaha MJ, et al. Heart disease and stroke statistics: 2016 update - A report from the American Heart Association. Circulation 2016; 133:e38-60. doi: 10.1161/CIR. 0000000000000350.

2. World Health Organisation. Cardiovascular diseases (CVDs). From: www.who.int/mediacentre/factsheets/fs317/en/ Accessed: Oct 2016.

3. Celermajer DS, Chow CK, Marijon E, Anstey NM, Woo KS. Cardiovascular disease in the developing world: Prevalences, patterns, and the potential of early disease detection. J Am Coll Cardiol 2012; 60:1207-16. doi: 10.1016/j.jacc.2012.03.074.

4. Achari V, Thakur AK. Association of major modifiable risk factors among patients with coronary artery disease: A retrospective analysis. J Assoc Physicians India 2004; 52:103-8.

5. Jhamnani S, Patel D, Heimlich L, King F, Walitt B, Lindsay J. Meta-analysis of the effects of lifestyle modifications on coronary and carotid atherosclerotic burden. Am J Cardiol 2015; 115:268-75. doi: 10.1016/j.amjcard.2014.10.035.

6. Alm-Roijer C, Stagmo M, Udén G, Erhardt L. Better knowledge improves adherence to lifestyle changes and medication in patients with coronary heart disease. Eur J Cardiovasc Nurs 2004; 3:321-30. doi: 10.1016/j.ejcnurse.2004.05.002.

7. Ammouri AA, Tailakh A, Isac C, Kamaniyre JK, Muliira J, Balachandran S. Knowledge of coronary heart disease risk factors among a community sample in Oman: Pilot study. Sultan Qaboos University Med J 2016; 16:e189-96. doi: 10.18295/squmj.2016.16.02.009.

8. Smith SC Jr, Benjamin EJ, Bonow RO, Braun LT, Creager MA, Franklin BA, et al. AHA/ACCF secondary prevention and risk reduction therapy for patients with coronary and other atherosclerotic vascular disease: 2011 update - A guideline from the American Heart Association and American College of Cardiology Foundation. Circulation 2011; 124:2458-73. doi: 10.1161/CIR.0b013e318235eb4d.

9. Goodman R. The strengths and difficulties questionnaire: A research note. J Child Psychol Psychiatry 1997; 38:581-6. doi: 10.1111/j.1469-7610.1997.tb01545.x.

\section{CPD CREDITS FOR AUTHORS}

Authors of articles published in SQUMJ may apply for category 1 continuing professional development (CPD) credits. The Oman Medical Specialty Board will award the following per publication:

- 5 credits to the first and corresponding authors;

- 3 credits to the second author;

- 2 credits to the third and subsequent authors. 